BNL $-81569-2008-C P$

\title{
14-MeV Neutron Generator Used as a Thermal Neutron Source
}

\author{
I. Dioszegi ${ }^{1}$, G. Smith ${ }^{1}$ and N. Schaknowski ${ }^{1}$ \\ ${ }^{1}$ Brookhaven National Laboratory, Upton, New York 11973 \\ Nonproliferation and National Security Department \\ Detector Development and Testing Division \\ Brookhaven National Laboratory \\ P.O. Box 5000 \\ Upton, NY 11973-5000 \\ www.bnl.gov
}

Notice: This manuscript has been authored by employees of Brookhaven Science Associates, LLC under Contract No. DE-AC02-98CH10886 with the U.S. Department of Energy. The publisher by accepting the manuscript for publication acknowledges that the United States Government retains a non-exclusive, paid-up, irrevocable, worldwide license to publish or reproduce the published form of this manuscript, or allow others to do so, for United States Government purposes.

This preprint is intended for publication in a journal or proceedings. Since changes may be made before publication, it may not be cited or reproduced without the author's permission. 


\section{DISCLAIMER}

This report was prepared as an account of work sponsored by an agency of the United States Government. Neither the United States Government nor any agency thereof, nor any of their employees, nor any of their contractors, subcontractors, or their employees, makes any warranty, express or implied, or assumes any legal liability or responsibility for the accuracy, completeness, or any third party's use or the results of such use of any information, apparatus, product, or process disclosed, or represents that its use would not infringe privately owned rights. Reference herein to any specific commercial product, process, or service by trade name, trademark, manufacturer, or otherwise, does not necessarily constitute or imply its endorsement, recommendation, or favoring by the United States Government or any agency thereof or its contractors or subcontractors. The views and opinions of authors expressed herein do not necessarily state or reflect those of the United States Government or any agency thereof. 


\section{ID 174} model for the MCNP5 ${ }^{1}$ and MCNPX ${ }^{2}$ simulations is shown in Fig. 1.

\section{Abstract ID Number: \#174}

\section{PACS code- 29.25 Dz, Neutron sources, 28.41.Qb Shielding (Nuclear technology)}

\section{Keywords: Neutron, Monte Carlo method, Shielding}

\section{4-MeV Neutron Generator Used As a Thermal Neutron Source}

\author{
I. Dioszegi ${ }^{1}$, G. Smith ${ }^{1}$ and N. Schaknowski ${ }^{1}$ \\ ${ }^{1}$ Brookhaven National Laboratory, Upton, New York 11973, USA.
}

Abstract: One of the most important applications of the general purpose Monte Carlo N-Particle (MCNP5 and MCNPX)) codes is neutron shielding design. We employed this method to simulate the shield of a 14-MeV neutron generator used as a thermal neutron source providing an external thermal neutron beam for testing large area neutron detectors developed for diffraction studies in biology and also useful for national security applications.

Nuclear reactors have been the main sources of neutrons used for scientific applications. In the past decade, however, a large number of reactors have been shut down, and the importance of other, smaller devices capable of providing neutrons for research has increased. At Brookhaven National Laboratory a moderated Am-Be neutron source with shielding is used for neutron detector testing. This source is relatively weak, but provides a constant flux of neutrons, even when not in use. The use of a $14 \mathrm{MeV}$ energized neutron generator, with an order of magnitude higher neutron flux has been considered to replace the Am-Be source, but the higher fast neutron yield requires a more careful design of moderator and shielding. In the present paper we describe a proposed shielding configuration based on Monte Carlo calculations, and provide calculated neutron flux and dose distributions.

We simulated the neutron flux distribution of our existing Am-Be source surrounded by a paraffin thermalizer cylinder (radius of $17.8 \mathrm{~cm}$ ), $0.8 \mathrm{~mm}$ cadmium, and borated polyethylene as biological shield. The thermal neutrons are available through a large opening through the polyethylene and cadmium. The geometrical 


\section{ID 174}

1 We simulated the Am-Be source neutron energy distribution ${ }^{3}$ as a point source having an energy distribution of four

2 discrete lines at $3.0(37 \%), 5.0(35 \%), 8.0(20 \%)$ and $11.0(8 \%) \mathrm{MeV}$ energies. The estimated source strength based

3 on the original specifications is $6.6 \cdot 10^{6}$ neutrons/sec. The simulation accurately predicts the measured thermal

4 neutron flux at the collimator (Figure 2), thus providing validation for this method. Using MCNPX we simulated the

5 neutron and photon dose distribution and also obtained a good agreement with the measured values.

Having established a validated framework for the shield calculation we then scaled up the Am-Be

arrangement to simulate the shielding required for the higher neutron energy and flux of the neutron generator $\left(\sim 10^{8}\right.$

neutron/sec at $14 \mathrm{MeV}$ ). Given the physical dimensions of the generator we have chosen a cylindrical geometry, thermalizer is surrounded by $0.8 \mathrm{~mm}$ cadmium, and a cylindrical borated polyethylene shield. A cylindrical opening

11 (radius of $7.6 \mathrm{~cm}$ ) serves to direct the neutrons out towards the experimental area (on the right side). The initial 12 model is shown in figure 3.

13 The first goal of the calculations was to establish the minimal required radius of the biological shield. For

14 this purpose we performed MCNPX neutron and photon dose distribution calculations by tallying the absorbed dose

15 on a $200 \times 200 \mathrm{~cm}$ mesh in the vertical center plane superimposed over the geometry. Figure 4 . displays the neutron

16 dose distribution along the central horizontal (X) axis. As observed from the figure, a shielding radius of $\sim 80 \mathrm{~cm}$ is

17 sufficient to obtain a dose level of $<\sim 4 \mathrm{mrem} /$ hour outside the shield (except from the open neutron channel on the 18 right).

In the next step we studied the optimization of the thickness of the paraffin thermalizer by increasing the

20 depth of the neutron exit channel into the paraffin cylinder. It was found, that the thermal flux greatly increases if we 21 have thinner paraffin layer, an optimal value being about $5 \mathrm{~cm}$ thickness. But as a drawback the flux of fast neutrons 22 also increased. A thicker thermalizer layer, in fact, acts as shielding. A slightly off centered, tangential placement of 23 the neutron channel provides a solution which maximizes the thermal flux to fast neutron yield. Figure 5. and 6.

24 display the final results, where we included an outside biological shield $(20 \mathrm{~cm}$ thickness $)$ providing a shielded

25 experimental area. There is a $10-100 \mathrm{n} / \mathrm{cm}^{2} \mathrm{sec}$ flux near the neutron beam exit, and outside the shield the neutron dose is below 26 the radiation area limit $(\sim 5 \mathrm{mrem} / \mathrm{hour})$. 


\section{ID 174}

1 References:

2

3 1. MCNP5 User's Manual, LANL Report, LA-CP-03-0245, 2003

4

2. MCNPX User's Manual, LANL Report, LA-CP-07-1473, 2008

5

3. J. E. Lutkin, G. W. McBeth, Nucl. Instr. Meth. 107 (1973) 165-171.

6

7

8

9

10

11

12

13

14

15

16

17

18

19

20

21

22

23

24

25

26

27

28 
ID 174

1

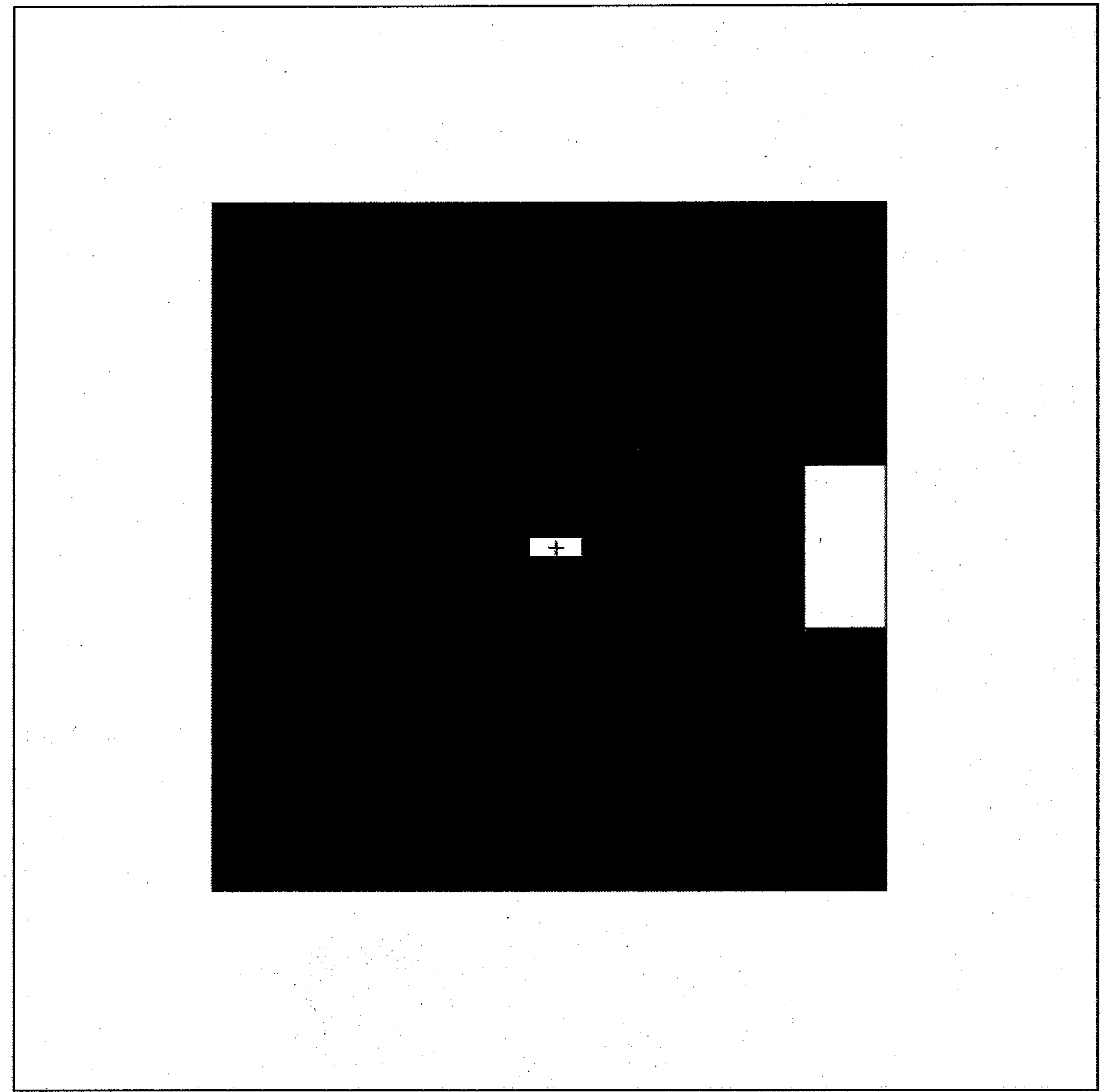

5 Fig. 1. Geometrical model for the Am-Be calculation. Purple: paraffin thermalizer, blue: cadmium, green: borated

6 polyethylene, yellow: air. The Am-Be source is at the center. The cylindrical setup is shown in the vertical cross section, 7 where it appears to be rectangular. The thin cadmium shielding is barely visible. 


\section{$\log 10$ of thermal neutron flux $/ 6^{*} 10^{6}$ source neutron (ambe5.1.6e6)}

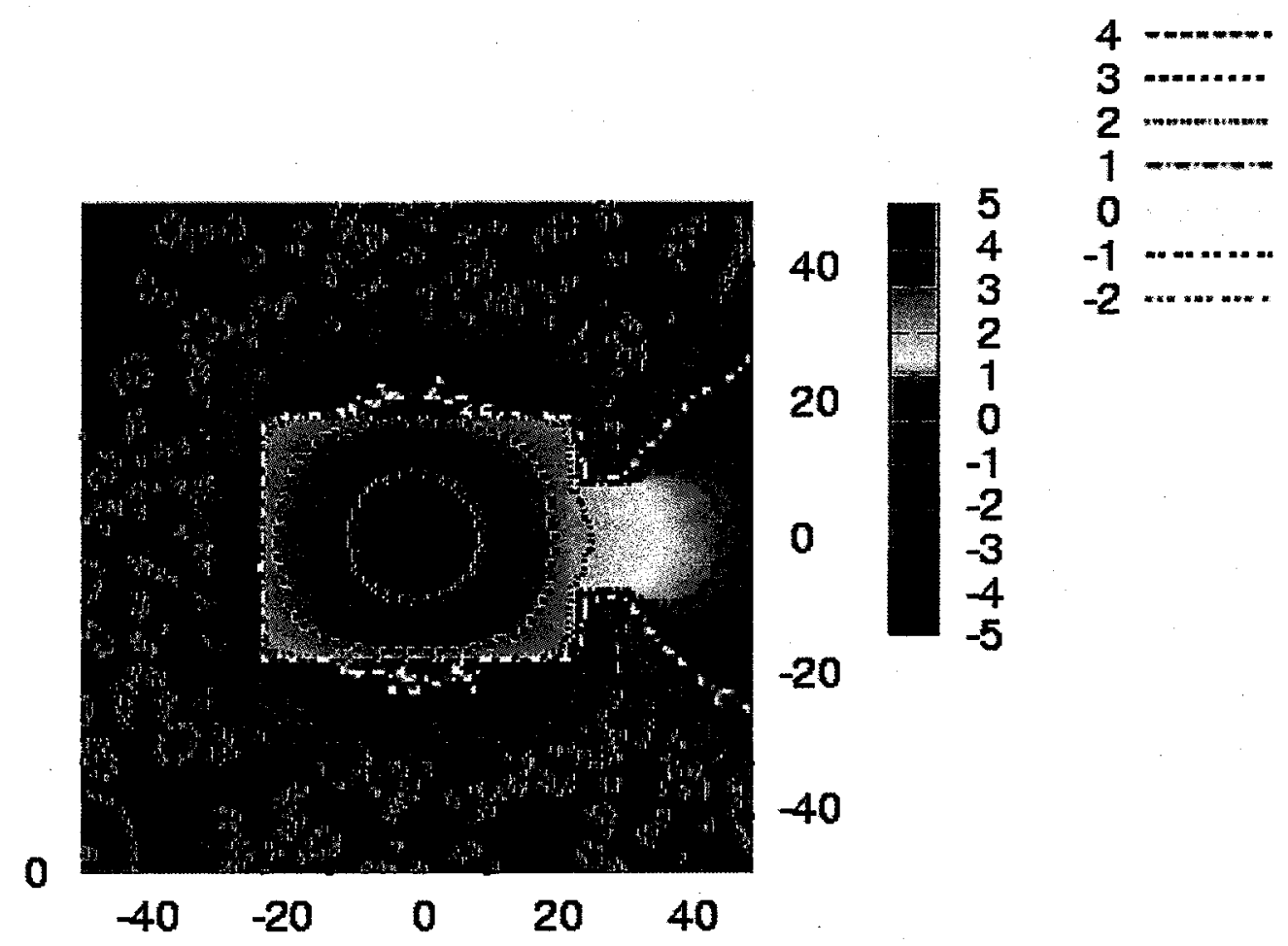

4 Fig. 2. MCNP5 mesh tally (in the central vertical plane, dimensions are in $\mathrm{cm}$ ) of the logarithmical thermal

5 flux distribution for $6.6 \times 10^{6}$ source neutrons. The calculated flux at the collimator is in good agreement with

6 the measured values. 
ID 174

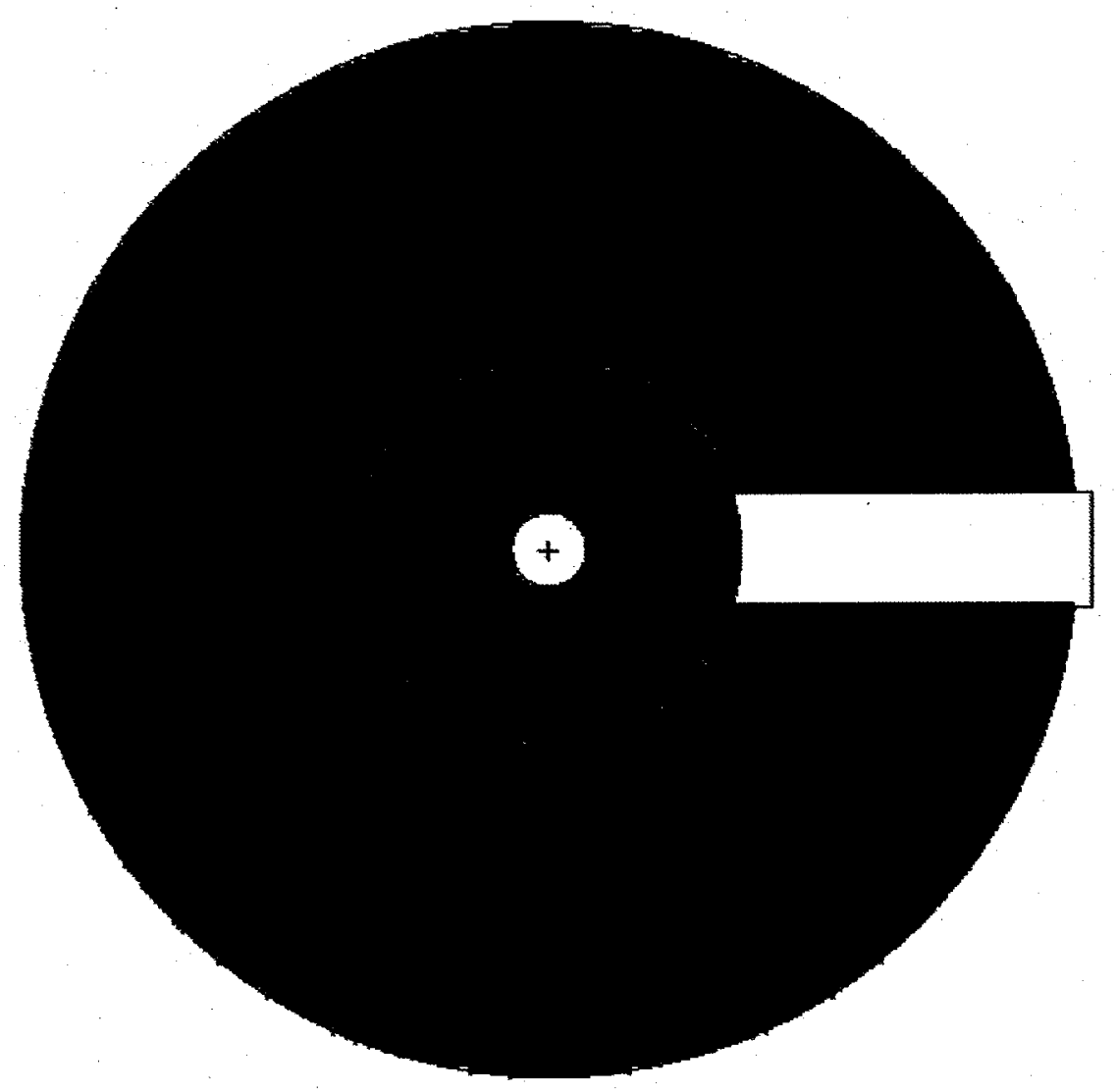

4

5 Fig. 3. Geometrical model (top view) for the 14-MeV calculations. Purple: paraffin thermalizer, blue: cadmium, green:

6 borated polyethylene, yellow: air. The neutron generator target located at the center of the picture.

7

8

9 
ID 174

2

3
4

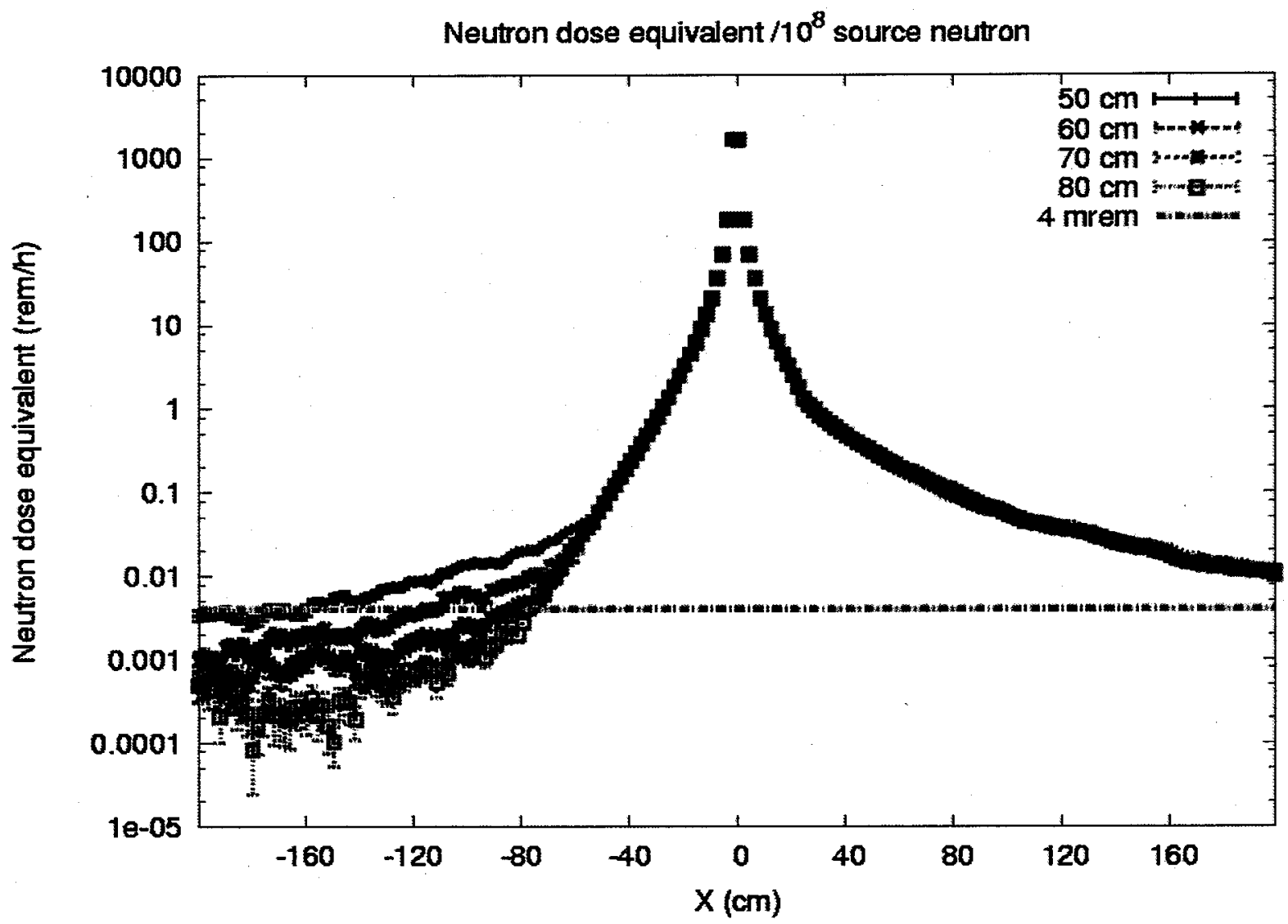

5

7 Fig. 4. Neutron dose equivalent (in rem/h) as a function of shielding radius. At about $\sim 80 \mathrm{~cm}$ radius the dose falls below $\sim 4$

8 mrem outside the shield.

9

10

11

12

13

14

15

16 


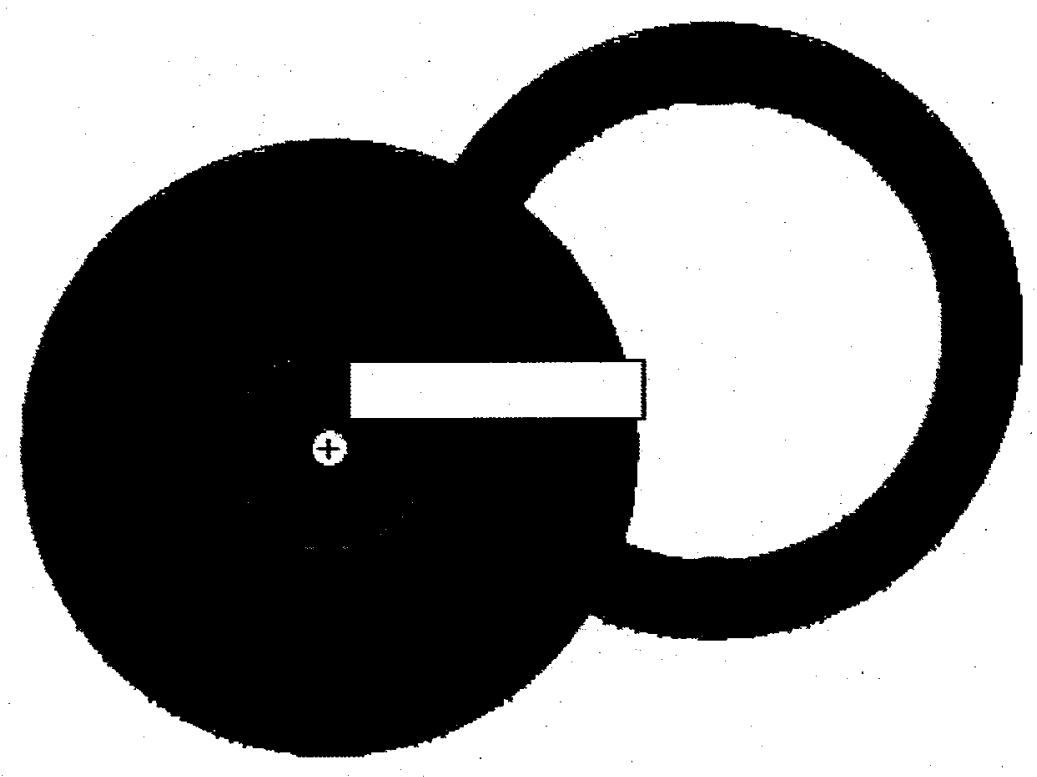

3 Fig. 5. The final model, including a shielded experimental area.

4 


\section{ID 174}

Log10 of thermal neutron flux $/ 1$ e8 source neutron in (nflux $25.5-115.70 \mathrm{~cm}$-shielded-th)

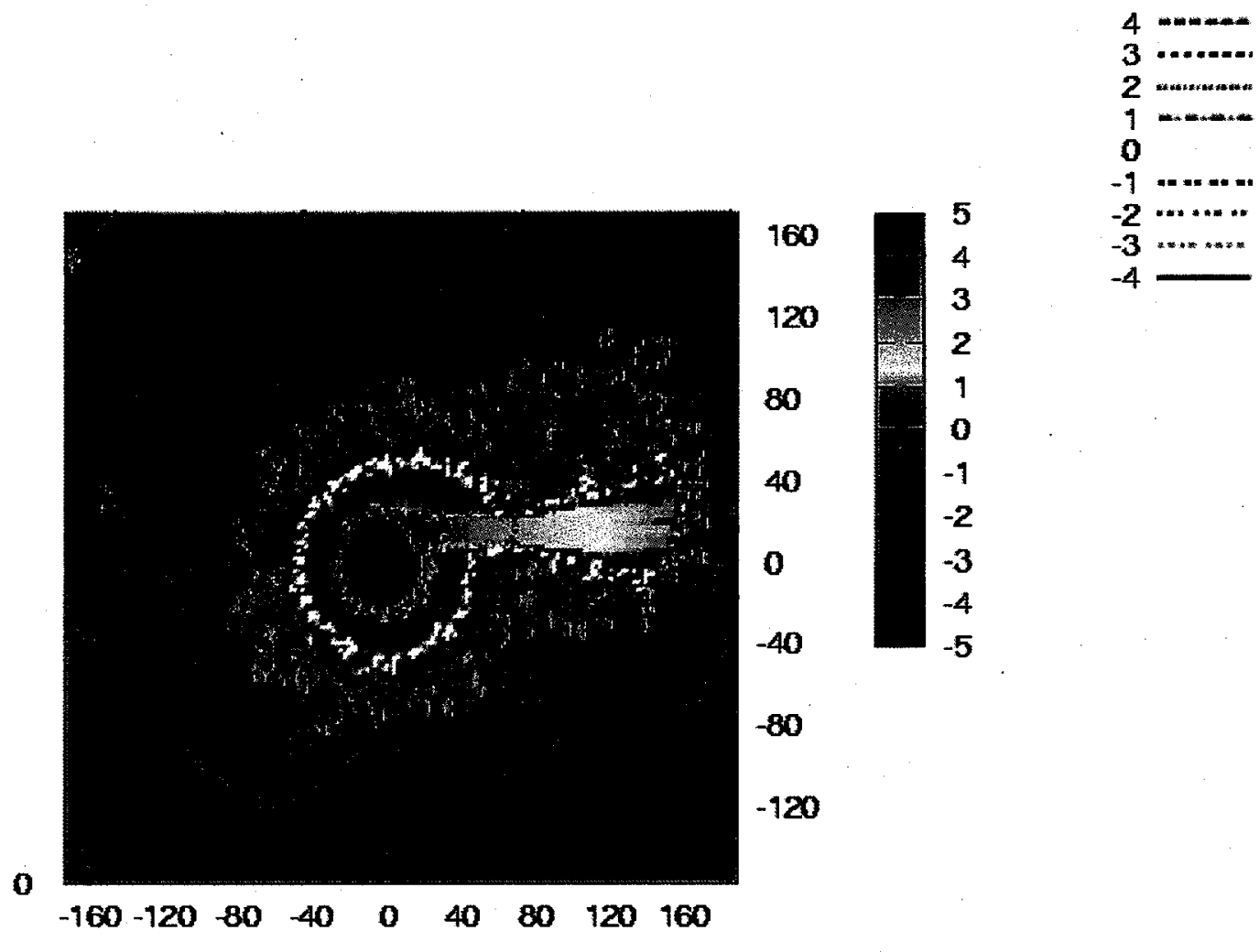

1

2 Fig. 6. Logarithmic thermal neutron flux distribution corresponding to the final model calculation.

3

4 